\title{
Application of ground magnetic and multi-frequency EM techniques for the Abu-Shihat radioactive prospect area, North Eastern Desert, Egypt
}

\author{
Assran S.M. Assran \\ Nuclear Materials Authority, Cairo, Egypt
}

\begin{abstract}
Land magnetic and electromagnetic data enhancement procedures were employed to follow the extensions of the observed anomalies on the surface downwards in the deeper levels and to recognize any possible relations between the localization of uranium mineralization and both the structural and geologic settings. This study revealed that the Analytic Signal (AS) and high pass and low pass filtering approaches significantly improve the interpretability of the measured magnetic data in discriminating the shallow and deep magnetic sources within the Abu-Shihat prospect area. Furthermore, the EM survey using varying frequencies, coil separations and station separations was performed in the considered area with the horizontal-loop EM equipment. The interpretation of the horizontalloop EM data indicated the presence of some conductive zones. These zones are mainly associated with felsite and pegmatite dykes, as well as alteration and fault zones. The target parameters such as the location, width, depth, dip and conductivity thickness were estimated for each conductive zone. Combining the ground magnetic and horizontal-loop EM surveys with the geological and structural mapping revealed that the mineralizations are concentrated in the eastern and western parts of the study area, and these techniques are considered as valuable exploration tools for uranium associated sulfide mineralization.
\end{abstract}

Key words magnetic-analytic signal-wavelength filter - multi-frequency EM - geological mapping

\section{Introduction}

The Abu-Shihat prospect area $\left(26^{\circ} 38^{\prime} \mathrm{N}\right.$, $\left.33^{\circ} 24^{\prime} \mathrm{E}\right)$ is located about $8 \mathrm{~km}$ north of QenaSafaga road at El-Faroukiya station (85 km from Qena). The Nuclear Materials Authority (NMA) selected it through intensive geological, geochemical and geophysical studies.

Mailing address: Dr. Assran S.M. Assran, Nuclear Materials Authority, P.O. Box 530, Maadi Road Post Office, Cairo, Egypt; e-mail: assran@ @otmail.com
The geophysical investigation started by aerial radiometric and magnetic survey for the area bounded between latitudes $25^{\circ} 48^{\prime} \mathrm{N}$ and $26^{\circ} 44^{\prime} \mathrm{N}$ and longitudes $32^{\circ} 53^{\prime} \mathrm{E}$ and $33^{\circ} 34^{\prime} \mathrm{E}$ (Ammar, 1973), including the present prospect area (fig. 1). This investigation was followed by ground proving and checking of the recorded anomalies, accompanied by regional geological investigations, followed by semi-detailed and detailed radiometric investigations (El-Tahir, 1978; Bakhit et al., 1984).

The results of the previous radiometric and geochemical studies had identified three anomalous radiometric zones in the study area (ElTahir, 1978). Each of these locations was excavated with a front-loader. A relative increase in the uranium mineralization was found, mainly 


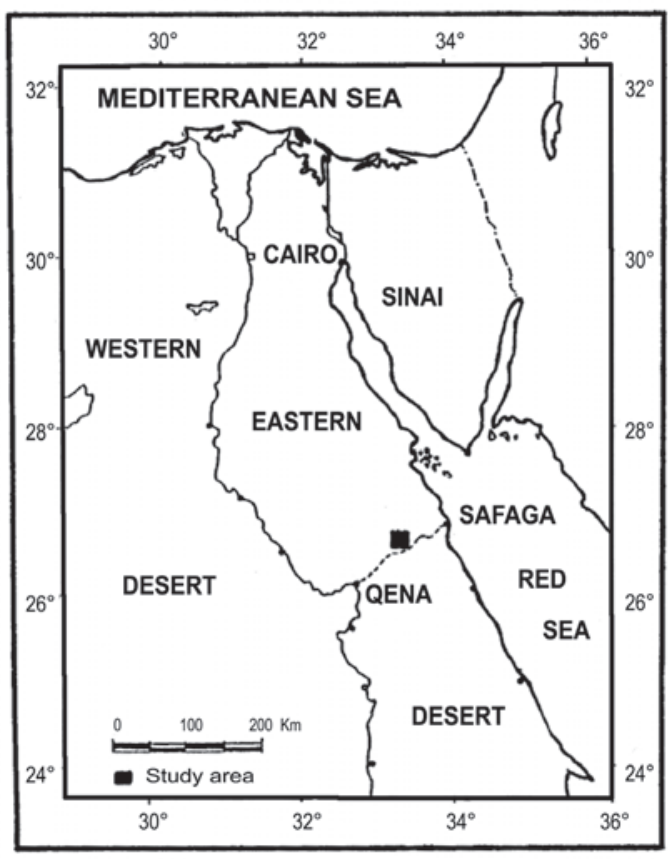

Fig. 1. Key map showing the location of the AbuShihat radioactive prospect area, North Eastern Desert, Egypt.

represented by secondary uranium minerals and some sulfide minerals in the highly fractured granites and granodiorites, as well as the felsitic and pegmatitic dykes. The radioactivity is ranged from 80 to $320 \mathrm{Ur}$ at the surface, with a maximum of $480 \mathrm{Ur}$ at about $1 \mathrm{~m}$ depth. El-Tahir (1978) recommended further geophysical and drilling investigations in a trial to discover any subsurface extensions of the uranium mineralizations.

Magnetic and electromagnetic techniques have historically been the most common geophysical methods used in mineral exploration. Both techniques are cost effective and the data can be interpreted quickly in the field. Often, the data resulting from the two methods are sufficient to characterize the buried targets (Won and Keiswetter, 1997). The present work deals with the application of ground magnetic, multifrequency and multi-separation EM survey, besides detailed geological mapping for the study area, to follow the extensions of the observed anomalies in the deeper levels, and to recognize any possible relations between the EM anomalies and magnetic anomalies, as well as the comparable geologic settings.

\section{Geologic setting}

The regional geology, structural set-up and potentialities of uranium in the Abu-Shihat area have been discussed by many workers (Schurmann, 1966; Sabet et al., 1972; Ghanem et al., 1973; El-Tahir, 1978; Bakhit et al., 1984). The author carried out a detailed geologic mapping for the prospect area (fig. 2). Accordingly, the study area is formed mainly of Precambrian basement rocks including quartz diorites, granodiorites and granites. These rocks are injected into the area by numerous pegmatitic, felsitic, quartzitic and basic dykes, and are locally covered by Quaternary sediments, which are represented by wadi (valley) sediments. These rocks were exposed to different tectonic events that produced various secondary structural elements as faulting and shearing in the N-S, NE-SW, ENE-WSW and NW-SE directions, beside the other minor trends.

\section{Ground magnetic survey}

\subsection{Magnetic data acquisition and correction}

A total magnetic field intensity survey was performed on a set of parallel $\mathrm{N} 60^{\circ} \mathrm{W}$ profiles normal to the general strike of the mineralized felsite dykes. The line spacing was $50 \mathrm{~m}$ and the measurements were taken at $20 \mathrm{~m}$ intervals along the survey profiles. Two tie lines were conducted (coded 00 and 300) normal to the observed profiles for controlling the consistency and reliability of the data. Two proton magnetometers (model PMG-1, Geofyzika, Brno, Czech Republic) were used: one for mobile station readings and the other for the base station readings. Base station readings were recorded every $30 \mathrm{~s}$ and used to correct for diurnal drift. The corrected values were then reduced to an 


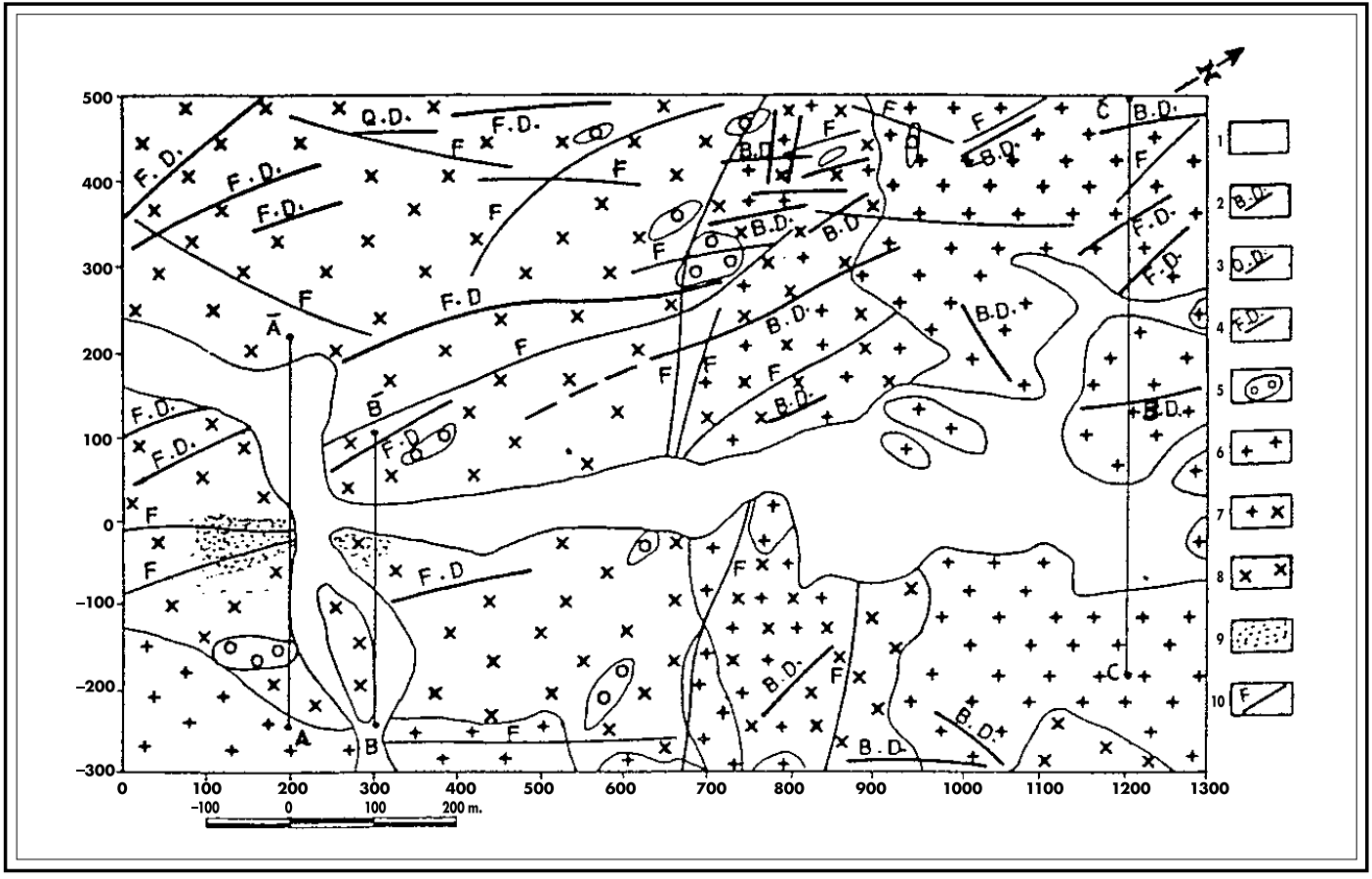

Fig. 2. Detailed geological and structural map of the Abu-Shihat radioactive prospect area, North Eastern Desert, Egypt, showing the 3 lines selected for EM survey. Symbols are: 1 = wadi sediments; 2 = basic dykes; $3=$ quartz dykes; $4=$ felsite dykes; $5=$ pegmatite dykes; $6=$ pink granites; $7=$ granodiorites; $8=$ diorites; $9=$ alteration zones, and $10=$ fault.

arbitrary datum (41800 nT) and the resulting data used to generate a total intensity magnetic map (fig. 3).

\subsection{The total intensity magnetic map}

According to the visual inspection of the total magnetic map (fig. 3), three magnetic zones of various magnetic characteristics were distinguished on the basis of the differences in the character of the magnetic anomalies i.e. their wavelengths, amplitudes and trend patterns. The first zone (Z1) covers the western and northwestern parts of the study area and is associated with felsite, quartz dykes and diorite rocks. It is occupied by broad belts of low frequencies having nearly a NNW-SSE direction. This zone decreases gradually in magnitude towards its western part, where its amplitude reaches - 95 nT. The second zone $(\mathrm{Z} 2)$ is situated at the central part of the area and is characterized by a group of relatively strong positive anomalies with a maximum amplitude of about $318 \mathrm{nT}$. These anomalies are associated with the basic dykes and diorite rocks (fig. 2). They trend in the N-S, NNE-SSW and NW-SE directions. The third zone (Z3) is located at the eastern part of the area and is associated with the pink granites and granodiorites. The northern part of this zone is represented by negative and positive closures of relatively small sizes and varying amplitudes, which may indicate that the causative bodies might be exiting at shallow depths. Meanwhile, the southern part is occupied by a negative rectangular belt and is divided into small negative 


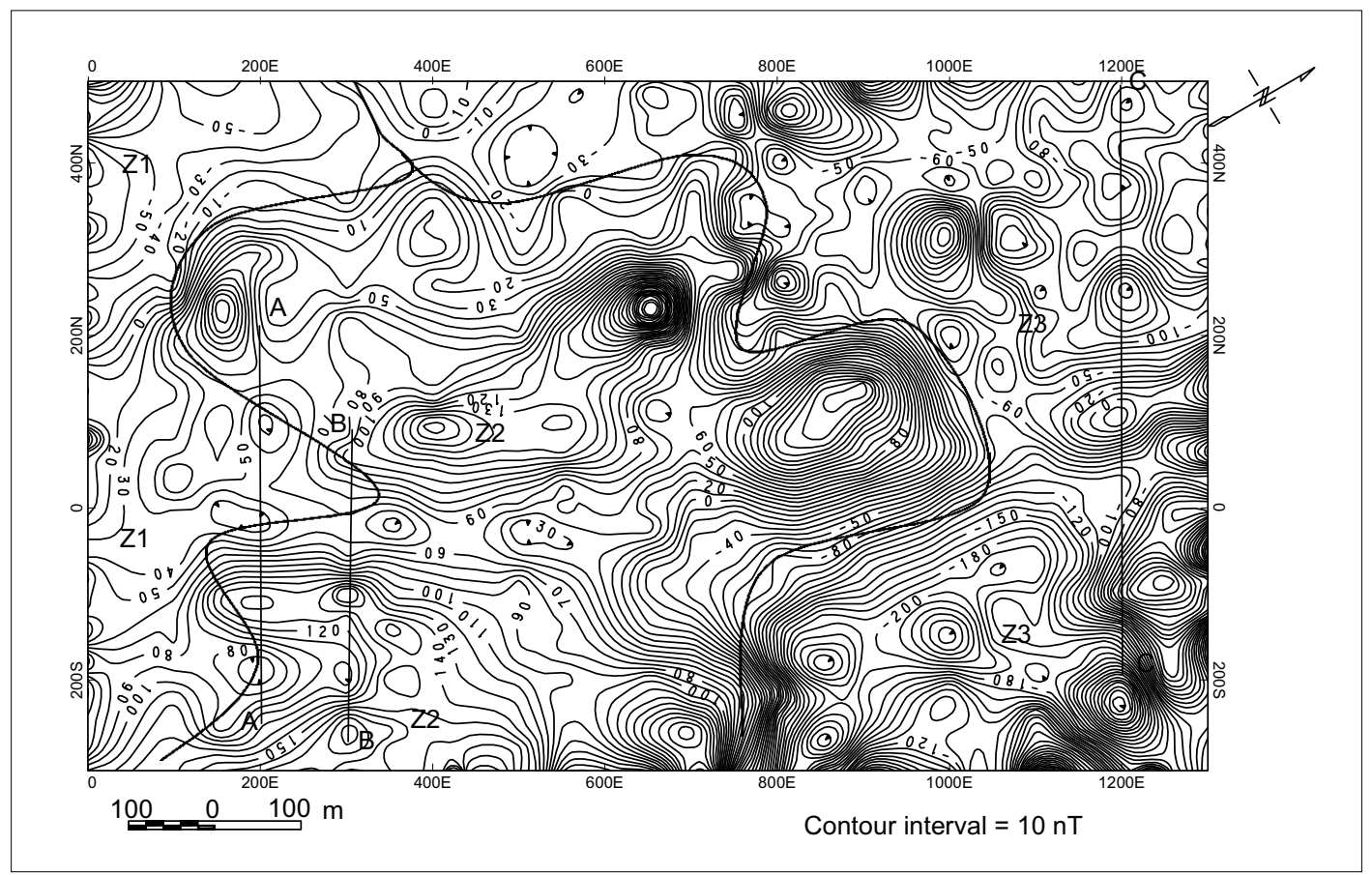

Fig. 3. Total intensity magnetic map of the Abu-Shihat radioactive prospect area, North Eastern Desert, Egypt.

anomalies trending mainly in the N-S and E-W directions. This may indicate the existence of small separate magnetic bodies resting over a deeper one.

\subsection{Analytic signal map}

The Analytic Signal (AS) has been shown to be effective in interpreting the subsurface magnetic contacts (e.g., Nabighian, 1972, 1974). This method does not require reduction to pole processing. A geologic contact or fault with significant susceptibility contrast is detected by mapping the maxima of the simple analytic signal, which is composed of two horizontal and one vertical gradients (Nabighian, 1972, 1974, 1984; Roest et al., 1992). Visual inspection of the analytic signal map (fig. 4) exhibits a number of maxima that conform very well with to the structural trends and geologic rock boundaries.
The western part of the map is occupied by relatively low frequency anomalies, which may reflect the deep sources at this part and also confirm the results obtained from the total intensity magnetic map (fig. 3). The small highs within this part are associated with felsite and pegmatite dykes, where each peak corresponds to one of the dykes appears. Meanwhile, the eastern part is characterized by high anomalies, which generally coincide with pink granites. Also, it seems obvious from the southeastern part that, the pink granites and granodiorites have small highs within a larger one. This may reflect a wide aerial extent below thin veneers of the rocks at this part. These high anomalies are separated by relatively low amplitudes and are associated with diorites (fig. 2). Therefore, from the above mentioned considerations, it can be concluded that the AS is a very good tool that can be used in differentiating the various rock types and delineating the structural trends 


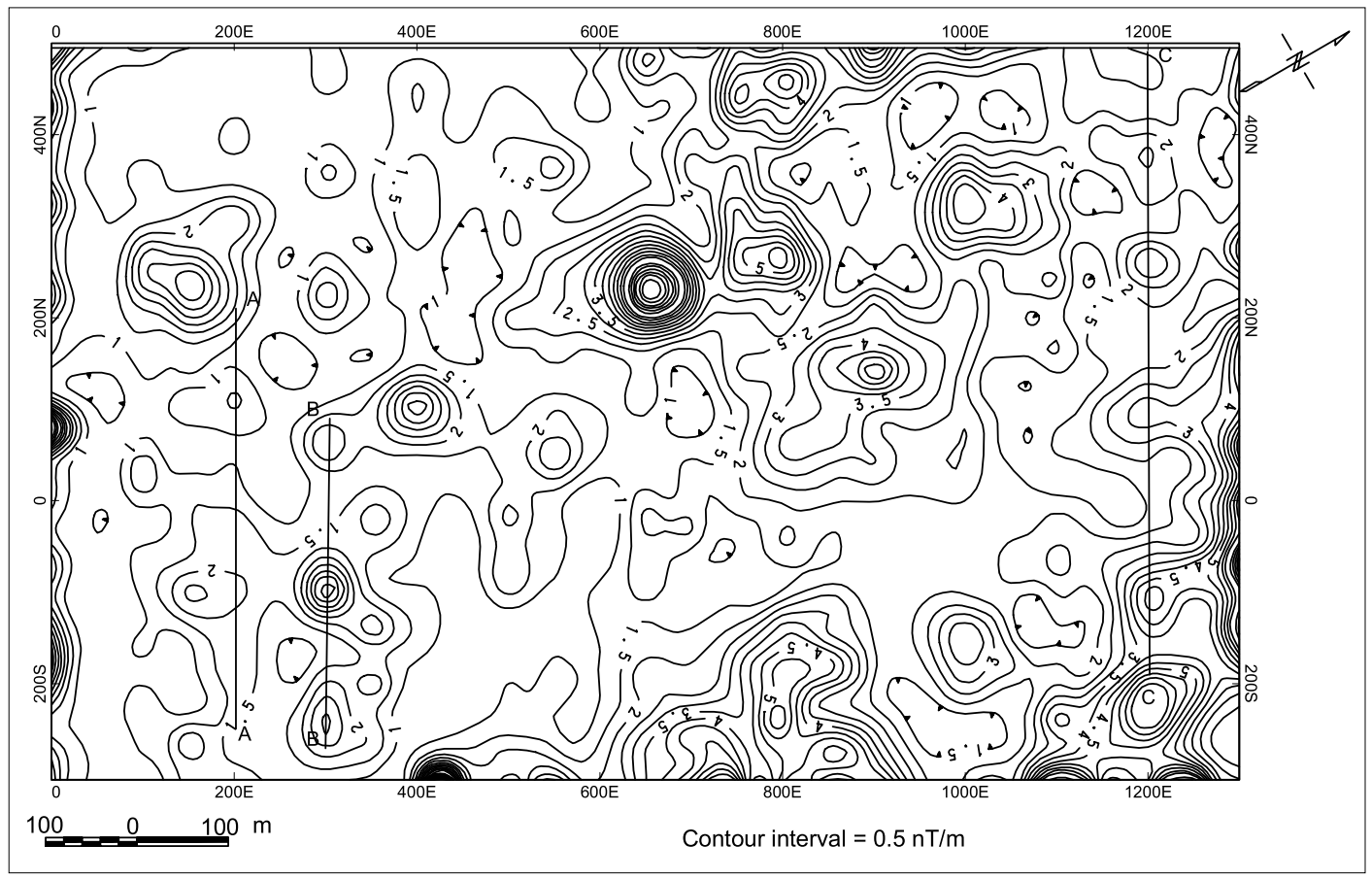

Fig. 4. Analytic signal of the total intensity magnetic map of the Abu-Shihat radioactive prospect area, North Eastern Desert, Egypt.

that may be obscured in the total intensity magnetic map.

\subsection{Regional-residual separation}

Magnetic data observed in geophysical surveys are the sum of magnetic fields produced by all the underground sources. The targets for specific surveys are often small-scale structures that occurred at shallow depths. The magnetic responses of these targets are embedded in a regional field, which arises from magnetic sources usually larger or deeper than these targets. Correct estimation and removal of the regional field from the initial effect yields the residual response produced by the target sources.

In the present study, the Fast Fourier Transform (FFT) was applied on the total intensity magnetic data using Geosoft Package (1994) to explore the frequency content of these data. As a result of visual inspection of the two-dimensional power spectrum (fig. 5), two linear segments were distinguished and fitted. The first segment lies at the low frequency (long wavelength) with a steep slope, related to the deep and/or broad causative magnetic sources. Meanwhile, the second segment is located at high frequency (short wavelength) with a gentle slope and is due to relatively shallow sources. The slope of a line fitted to each of the first and second segments of the spectrum curve is used to estimate the average depths of the regional and residual sources. These depths were recomputed with the power-low correction (Fedi et al., 1997). The estimated average depths to the regional and residual sources are 53.1 and $12.4 \mathrm{~m}$, respectively. Moreover, the analysis of the power spectrum curve shows that the deepseated magnetic component frequency varies from 0 to 6 cycles $/ \mathrm{km}$, while the near-surface magnetic component frequency ranges from 6 


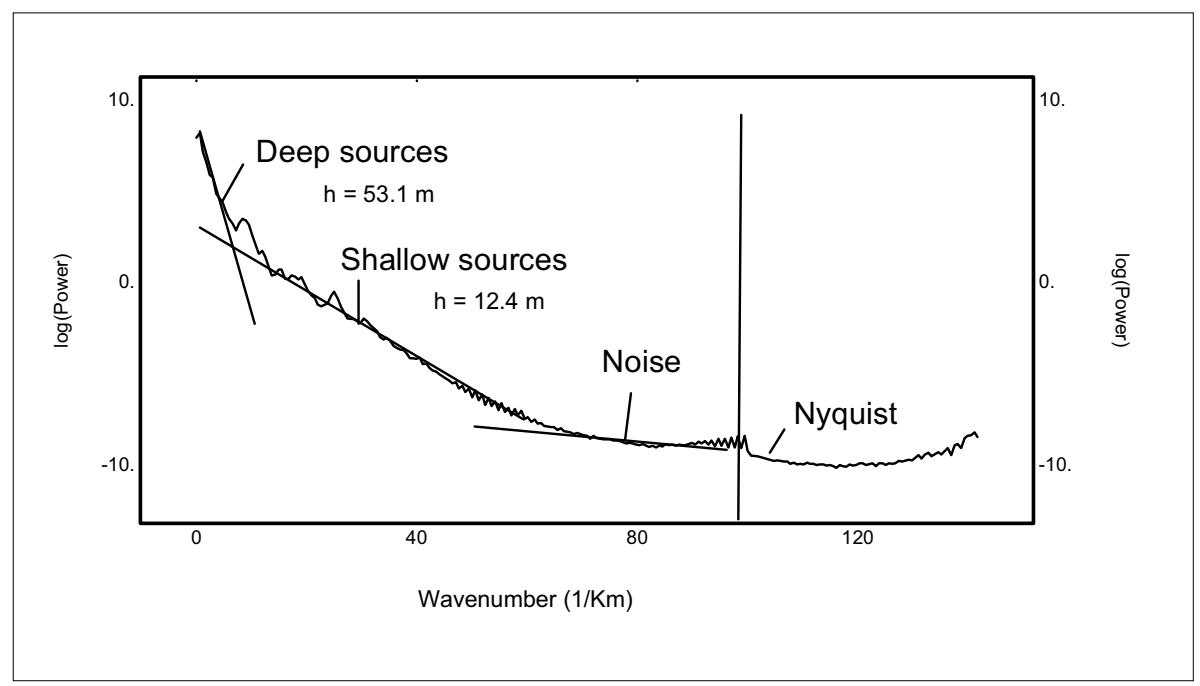

Fig. 5. Radially averaged power spectrum and depth estimate of the total intensity magnetic map of the AbuShihat radioactive prospect area, North Eastern Desert, Egypt.

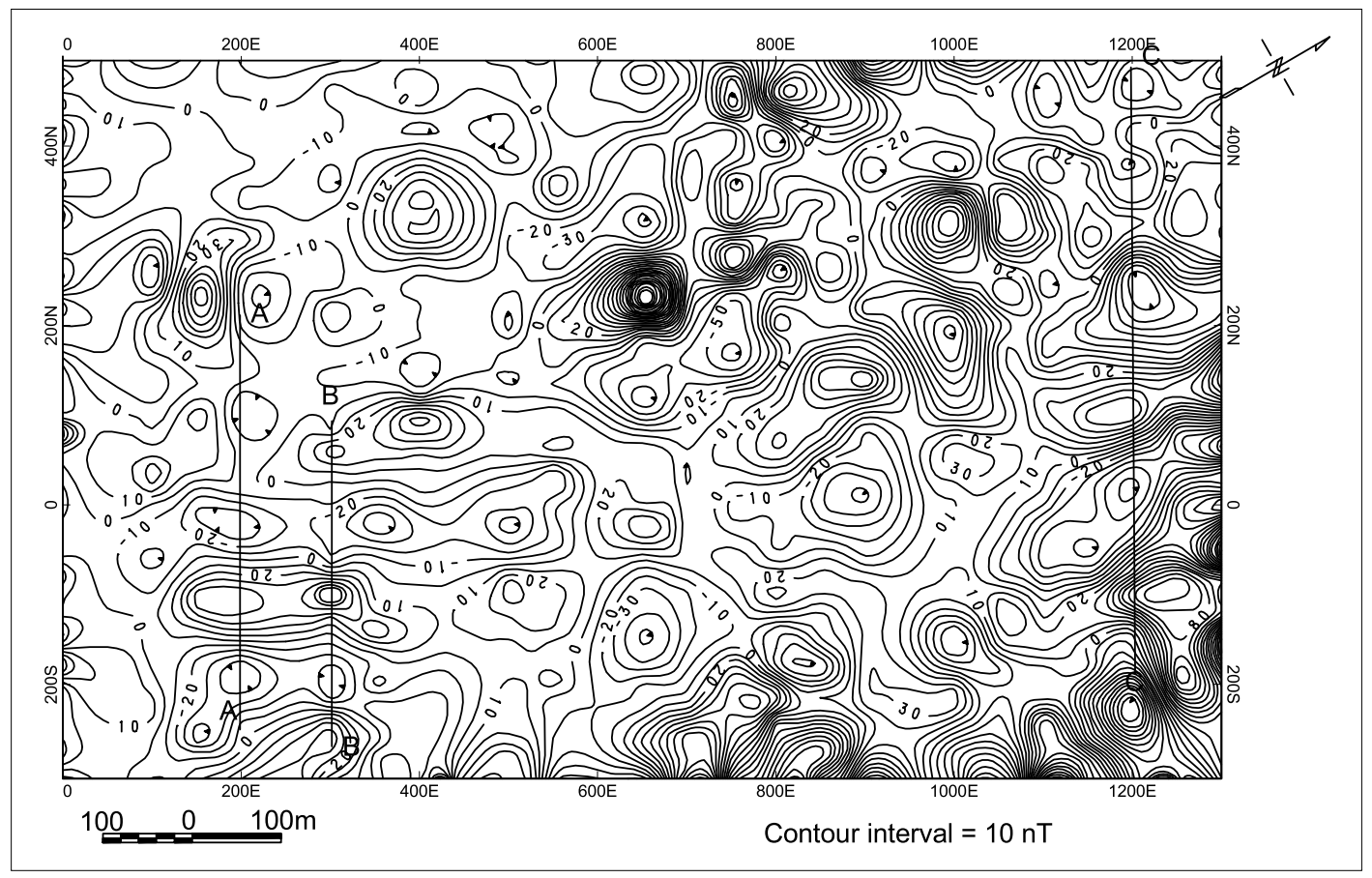

Fig. 6. High-pass filtered (frequency $=6-65 \mathrm{cycles} / \mathrm{km}$ ) magnetic map of the Abu-Shihat radioactive prospect area, North Eastern Desert, Egypt. 
to 65 cycles $/ \mathrm{km}$. These bands of frequency were used through the band-pass filter technique to produce the residual and regional component maps (figs. 6 and 7).

\subsubsection{The high-pass (residual) magnetic anomalies}

The residual magnetic anomalies can be defined as the anomalies that are economically interesting, because they indicate shallow anomalies and are characterized by weaker and more localized anomalies. The high-pass filtered map (fig. 6) reveals that the study area is characterized by small closures with semicircular to circular shapes and relatively high positive and negative amplitudes. The causative bodies of these closures might be cropped out or buried at shallow depths. Besides, relatively broad anomalies of deeper origin with low slopes and smooth shapes having relatively low amplitudes were seen. The residual anomalies are frequently preferred in the N-S, NW-SE and NE-SW directions and most of them are not shown clearly on the total intensity magnetic map (fig. 3).

\subsubsection{The low-pass (regional) magnetic anomalies}

The regional magnetic anomalies are strong, broad, extend over large areas and usually have high amplitudes and low frequencies. These anomalies are of considerable significance in the regional tectonic studies of the basement complex and of secondary importance in mineral exploration. The low-pass filtered map (fig. 7) shows:

1) A huge zone of high magnetic anomalies at the central part of the study area, bounded from

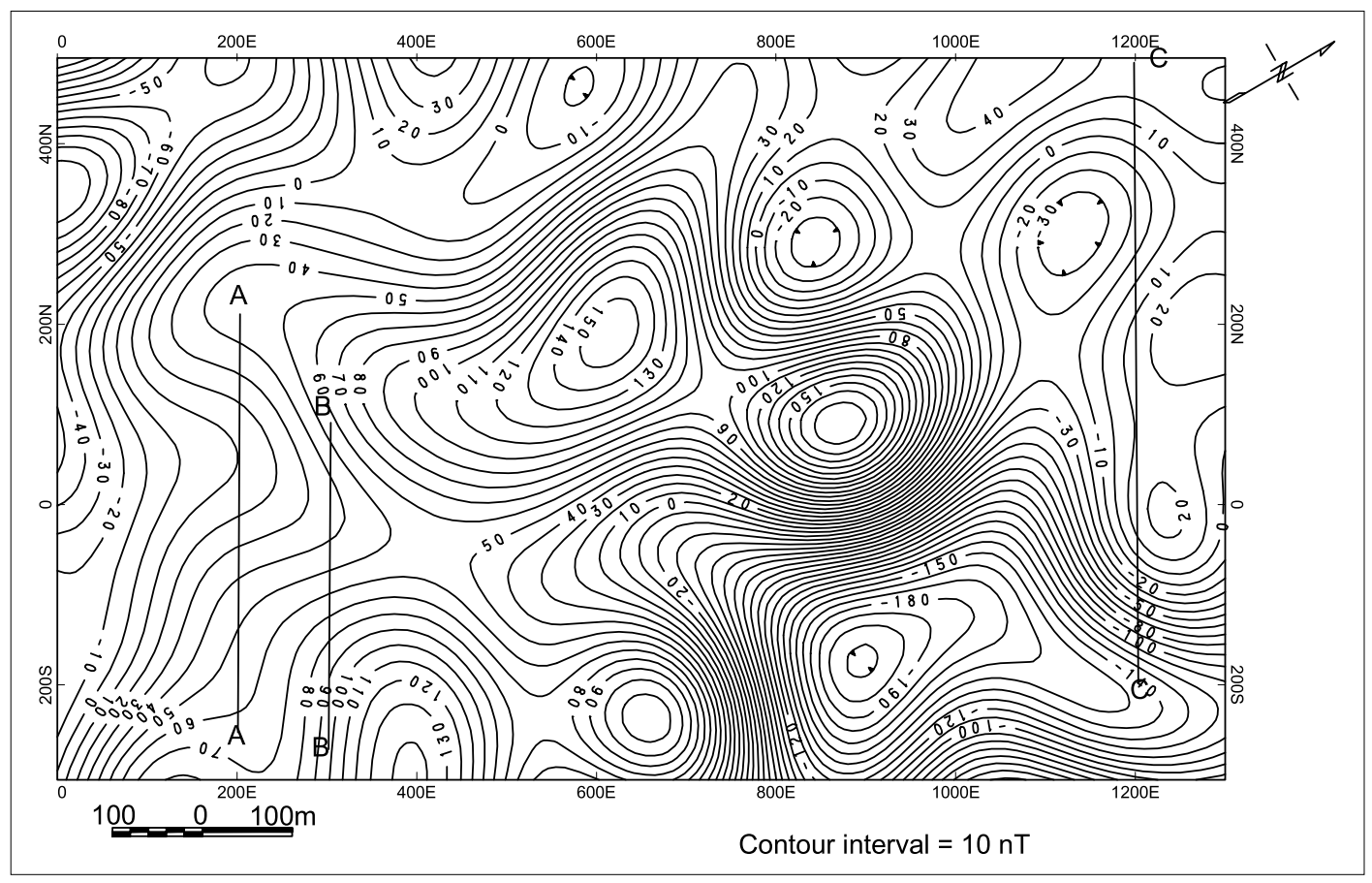

Fig. 7. Low-pass filtered (frequency $=6-65$ cycles $/ \mathrm{km}$ ) magnetic map of the Abu-Shihat radioactive prospect area, North Eastern Desert, Egypt. 
the west, north and east by relatively steep magnetic gradients. This may suggest the existence of major deep-seated faults bounding this zone from the stated directions.

2) A broad negative magnetic anomaly located at the southeastern corner of the study area, approximately trending in a N-S direction and associated with the pink granites and granodiorites.

3) A negative magnetic belt located at the northwestern part, trending in the NNW-SSE direction and associated with a set of felsite and quartz dykes. This may suggest that, these dykes are relatively deep at this part.

4) The regional magnetic anomalies are elongated mainly in the N-S, NNE-SSW and E-W directions.

\section{Horizontal-loop electromagnetic survey}

The electromagnetic (EM) induction method can be used to infer the electrical conductivity of the subsurface at different depths of interest by changing the spacing between transmitter and receiver coils or the frequency of the transmitted field (Patra and Mallick, 1980; Won, 1980; Keiswetter and Won, 1997). The horizontal-loop electromagnetic (HLEM) method is based on the principle of inducing eddy currents in the earth with a transmitter coil (Tx), which generates a primary electromagnetic field. The strength of the induced current and consequently that of the secondary electromagnetic field is dependent on the conductivity, shape and size of the target body and its location relative to the transmitter-receiver positions. The in-phase and out-of-phase components of the resulting secondary electromagnetic field are recorded at frequencies 112.5, 337.5, 1012.5 and $3037.5 \mathrm{~Hz}$. The coil separation between the transmitter coil (Tx) and receiver coil $(\mathrm{Rx})$ was either 100 or $120 \mathrm{~m}$. The midpoint of the line joining the Tx-Rx is used as the measuring point. The HLEM measurements were acquired at station spaced 10 and $20 \mathrm{~m}$ apart along the survey line, using the TM-2 transmitter and IGS-2/EM-4 receiver (Scintrex Limited, Canada).

By judicious application of the multi-frequency techniques, it is possible to detect the weaker conductors (small width) and to derive detailed information on the parameters of the conductors, from the anomalies obtained with the HLEM method. Besides the detection of electromagnetic anomalies, the aim of an electromagnetic survey is to estimate the parameters of the causative conductors from details of the gained anomalies. The main characters of the HLEM interpretation are, the location, dip $(\theta)$, width $(w)$, depth of burial $(h)$ and conductance $(\sigma t)$. These parameters can be estimated by using a family of response diagrams and curves, which were designed by Nair et al. (1974). The first step in interpreting the HLEM data is to establish the background in-phase and out-of-phase values, away from the anomaly to be interpreted. According to the results formerly obtained from the radiometric and geochemical data (El-Tahir, 1978), the HLEM survey was conducted along three profiles (coded 200, 300 and 1200). The HLEM data, corrected for the first-order topographic effects, are shown in figs. 8, 9 and 10. The examination of these profiles led to the following observations.

\subsection{Line $200\left(A-A^{\prime}\right)$}

This profile was conducted between stations - 250 and 210 with coil separations 100 and $120 \mathrm{~m}$, and station intervals 20 and $40 \mathrm{~m}$. The HLEM data shown on this line (fig. 8) indicate the existence of two EM anomalies. The first is close to station -190 and is associated with the pegmatite body (fig. 2). The width of this anomaly is less than the coil separation and may be due to a thin conductor. The second one has a negative peak for the in-phase and out-of-phase, and extends from about station coded -40 to about station coded 100 . This anomaly coincides with a set of faults and an alteration zone, as shown on the geologic map (fig. 2).

The results of quantitative interpretation of the second anomaly are the width that is about $40 \mathrm{~m}$, the depth to the upper edge that attains $52 \mathrm{~m}$ and the approximate dip angle that reaches $60^{\circ}$ to the south. Meanwhile, a considerable increase in the conductance estimates was observed by decreasing the frequency from 12.1 mhos at $3037.5 \mathrm{~Hz}$ to 47.6 mhos at $112.5 \mathrm{~Hz}$. This effect is due to the body thickness and the current 


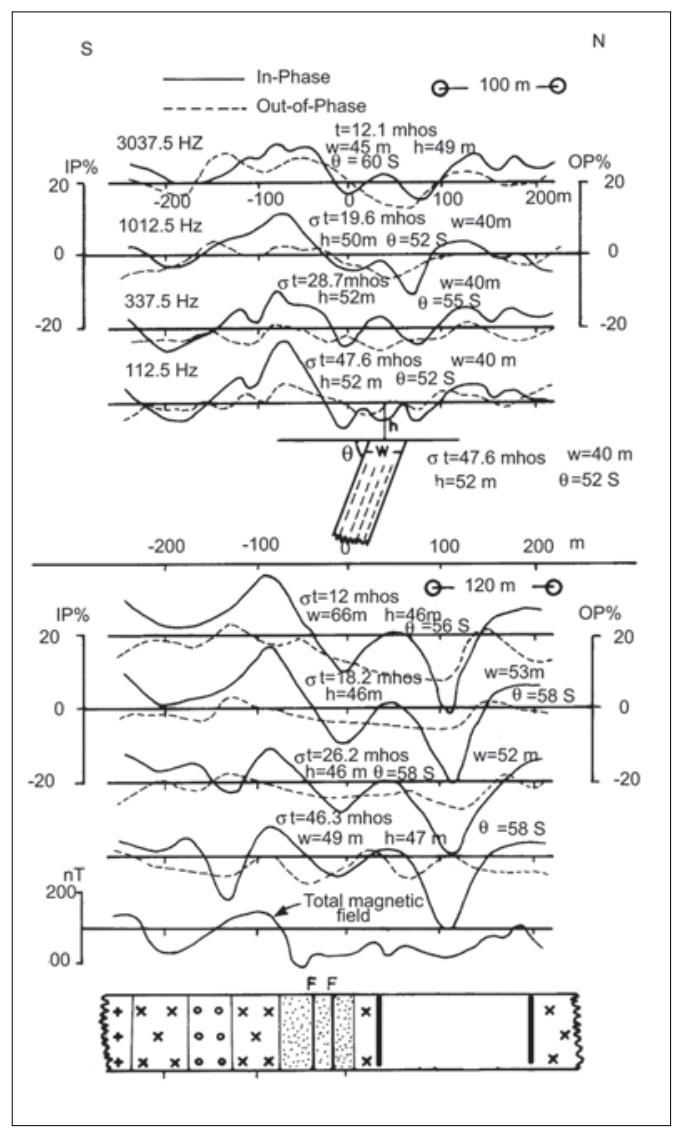

Fig. 8. Horizontal-loop EM profiles at several frequencies, coil separations and station separations with the corresponding total magnetic field profile along line A-A' (line 200) and surface geology of the AbuShihat radioactive prospect area, North Eastern Desert, Egypt. Symbols as in fig. 2.

gathering, a conclusion also supported by the results obtained by Betz $(1975,1976)$ for ground EM measurements and by Palacky (1978) for airborne EM surveys. Comparing the estimated depth, dip and conductance measured using the coil separations 100 and $120 \mathrm{~m}$, they are highly similar, but the width estimates increase with increasing spacing. This effect can be explained by the fact that, the values of the in-phase and out-of-phase components are primarily affected by dimensions of the conductor being investi- gated and its position in relation to the coil positions and coil separation.

The first EM anomaly coincides with low magnetic amplitudes and high frequencies (figs. 3, 4 and 7). This may indicate that, the causative body lies within shallow depths. Also, the second EM coincide with low magnetic amplitudes and low frequencies (figs. 3, 4, 6 and 7). This may reveal that, the causative body is relatively deep at this part. The estimated depth of the second anomaly agrees well with the average depths of the deep magnetic anomaly sources. Because of the high radiometric values (El-Tahir, 1978) in this zone, which is associated with the high conductance and low magnetic values at this part, a more detailed ground survey of this zone is recommended.

\subsection{Line $300\left(B-B^{\prime}\right)$}

This profile was carried out between stations - 270 and 90, with coil separation $100 \mathrm{~m}$ and station interval $20 \mathrm{~m}$. Only one broad conductive zone is indicated by a negative peak that extends from about station -220 to about station -60 (fig. 9). This zone corresponds to the extension of a geologically-mapped felsite dyke and the intersecting faults (fig. 2). The shapes of the inphase and out-of-phase components suggest two conductors spaced $60 \mathrm{~m}$ apart, as the maximum negative peak values are separated by more than coil spacing of $60 \mathrm{~m}$. The northern shoulder of the in-phase and out-of-phase components is reduced appreciably at higher frequencies, indicating the existence of conductive bodies in this region. This is supported by the magnetic and radiometric data. Other researchers observed a reduction of the out-of-phase component in the field and modeled EM data (Lajoie and West, 1977).

The quantitative interpretation of the HLEM data exhibits the width of the conductive zone as $60 \mathrm{~m}$, the dip angle as $32^{\circ}$ to the north, the depth to the upper edge attains $18 \mathrm{~m}$ and the conductivity thickness increases with decreasing frequency. It ranges from 4.8 to 22 mhos. This effect is due to the causative overburdens, which may cause phase rotations of the anomaly, resulting in the estimates of conductivity thickness decreasing with increasing frequency. 


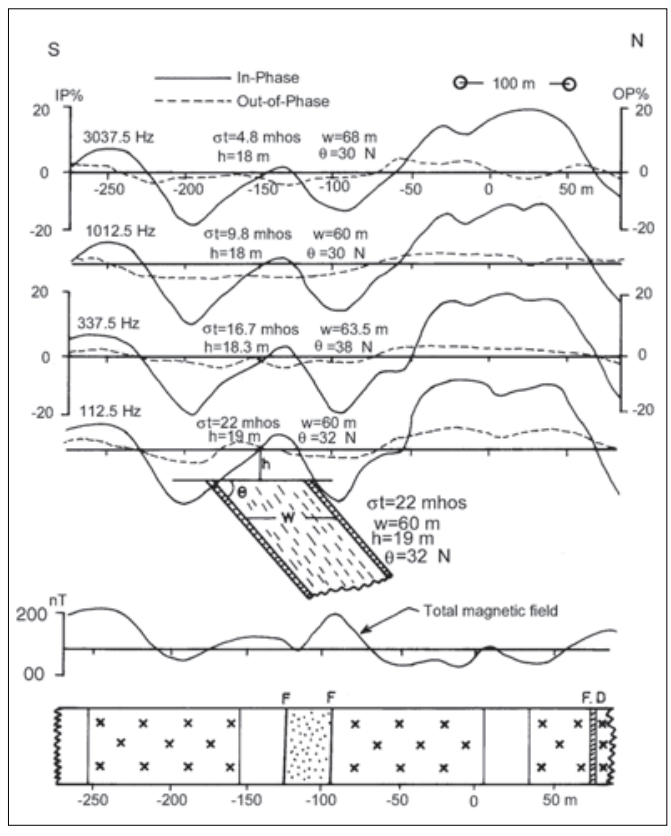

Fig. 9. Horizontal-loop EM profiles at several frequencies, coil separations and station separations with the corresponding total magnetic field profile along line B-B' (line 300) and surface geology of the AbuShihat radioactive prospect area, North Eastern Desert, Egypt. Symbols as in fig. 2.

On the high-pass filtered map (fig. 6), the EM conductive zone is represented by two belts of high frequencies and low magnetic amplitudes intruded by a belt of high magnetic amplitudes. Also, the low magnetic amplitudes coincide with the negative peaks of the in-phase and out-ofphase components. This may suggest that, two acidic causative bodies lie within the shallow depths.

\subsection{Line $1200\left(C-C^{\prime}\right)$}

This profile was conducted between stations - 190 and 490, with coil separations 100 and $120 \mathrm{~m}$, and station intervals 20 and $40 \mathrm{~m}$. The examination of HLEM data acquired along this line with coil separation $100 \mathrm{~m}$ exhibits a broad conductive zone at the northern part (fig. 10).
The shapes of the negative and positive peaks of the two components reveal that this zone is composed of a series of thin conductors over a width greater than $130 \mathrm{~m}$ of the coil spacing. On the magnetic maps (figs. 3 and 5), this zone is characterized by a group of relatively low magnetic amplitudes and high frequencies. This may reflect the causative bodies as acidic rocks, that lie within relatively shallow depths. Geologically, this zone coincides with a set of faults and felsite dykes (fig. 2).

The general parameters of the considered conductive zone $(\mathrm{Tx}-\mathrm{Rx}=100 \mathrm{~m})$ show that the width is about $130 \mathrm{~m}$, the depth to the upper edge reaches $26 \mathrm{~m}$, the dip angle is $62^{\circ}$ to the south

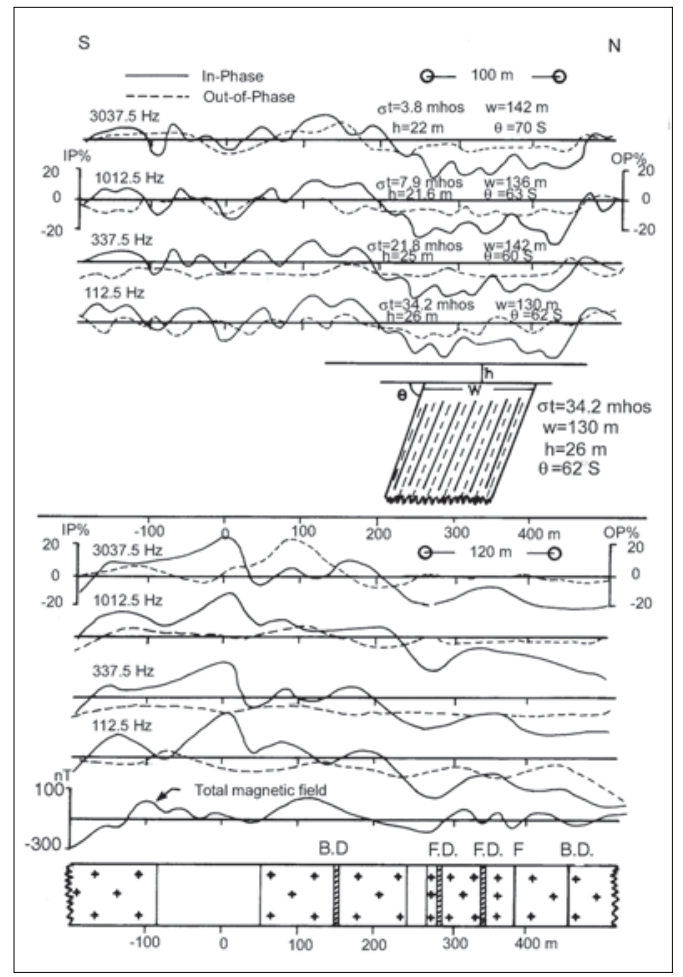

Fig. 10. Horizontal-loop EM profiles at several frequencies, coil separations and station separations with the corresponding total magnetic field profile along

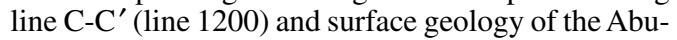
Shihat radioactive prospect area, North Eastern Desert, Egypt. Symbols as in fig. 2). 
and the conductivity thickness ranges from 3.8 mhos at $3037.5 \mathrm{~Hz}$ to 34.2 mhos at $112.5 \mathrm{~Hz}$. Meanwhile, the HLEM data with coil separation $120 \mathrm{~m}$ shows the existence of a broad and incomplete anomaly, whereas only one positive peak is present and the other one is outside the survey area. Besides, some of the anomalies in the in-phase and out-of-phase components are lost. This is often by apparent loss, because the smaller separation discriminates more effectively between the conductivities. Also, the positions of the peak values for the two components differ markedly, which may indicate that the observed anomaly represents the combined effect of two or more sources.

\section{Conclusions}

The visual inspection and analysis of the total intensity magnetic map and the other filtered magnetic maps revealed that the area concerned is generally characterized by a broad and high magnetic belt at the central part surrounded by low magnetic belts from the east and west. Besides, it includes surficial or local anomalies of shallow-seated origin, with narrow semicircular to circular shapes of relatively high amplitudes having N-S, NW-SE and NE-SW directions. The average estimated depth for the near-surface magnetic anomaly sources of the area is $12.4 \mathrm{~m}$, while that of the deep-seated anomaly sources is $53.1 \mathrm{~m}$.

The investigation of the horizontal-loop electromagnetic profiles reflected the occurrence of many conductive zones. These zones are mainly associated with a set of felsite dykes, alteration and fault zones. The conductive parameters, as estimated from the small coil separation and station interval, revealed widths ranging between 40 and $130 \mathrm{~m}$, shallow depths varying from 18 to $52 \mathrm{~m}$, dip angles ranging between $32^{\circ}$ and $62^{\circ}$, and conductivity thickness varying from 22 to 47.6 mhos for the mineralized zones. Comparing these values with the estimated values using larger coil separation and station interval, they are highly similar, but the width estimates increase with increasing spacing. This effect can be explained by the condition that the values of the in-phase and out-of-phase components are primarily affected by the dimensions of the conductor being investigated and its position in relation to the coils positions and coil separation. Besides, when large spacing is used, some of the anomalies are lost and the resolution of the individual conductor becomes poor, and if more than one conductor occurs, the interpretation of the results becomes difficult.

Because of the high radiometric anomalous zones, associated with the high conductive and low magnetic values, a more detailed ground survey of these zones and subsequent exploration drilling, based on the geophysical data are recommended to test the depths and grades of the probable mineralizations.

\section{Acknowledgements}

I would like to thank Professor Ahmed A. Ammar for fruitful discussions and valuable comments.

\section{REFERENCES}

Ammar, A. A. (1973): Application of aerial radiometry to the study of the geology of Wadi ElGdamiarea, Eastern Desert (with aeromagnetic application), Ph.D. Thesis, Faculty of Science, Cairo University, Giza, Egypt, pp. 424 (unpublished).

BAKHIT, F.S., M.L. MELEIK and M.A. El-TAHIR (1984): Correlation of the radiometric survey data and the structural analysis with the geology of Abu-Zawal area, Central Eastern Desert, Egypt, Geol. Rundsc., 73 (2), 833-851.

BETZ, J.E. (1975): Test program report with additional comments on the Max Min II electromagnetic system, Markham, APEX parametrics Ltd., pp. 34.

BETZ, J.E. (1976): Considerations behind the making of a well-rounded exploration system, Markham, APEX parametrics Ltd., pp.14.

EL-TAHIR, M.A. (1978): Relation between geology and radioactivity of some basement rocks to the north of QenaSafaga asphaltic road, Eastern Desert, Egypt, M.Sc. Thesis, Al Azhar University, Cairo, Egypt (unpublished).

FEDI, M., T. QuARTA and A. DE SANTIS (1997): Inherent power-law bahaviour of magnetic field power spectra from a Spector and Grant ensemble, Geophysics, 62, 1143-1150.

GEOSOFT PACKAGE (1994): Geosoft Mapping and Processing System, Geosoft Inc., Toronto.

GHANEM, M., A.A. DARDIR, M.H. RANCIS, A.A. ZalatA and K.M. ABU-ZEID (1973): Basement rocks in the Eastern Desert of Egypt north of latitude $26^{\circ} 40^{\prime} \mathrm{N}$, Ann. Geol. Surv., Egypt, 3, 33-38. 
KeISWETtER, D. and I. WON (1997): Multi-frequency electromagnetic signature of the cloud chamber, Nevada test site, J. Environ. Eng. Geophys., 2, 99-103.

LAJOIE, J.J. and G.F. WEST (1977): Two selected field examples of EM anomalies in a conductive environment, Geophysics, 42, 655-660.

NABIGHIAN, M.N. (1972): The analytic signal of twodimensional magnetic bodies with polygonal crosssection: its properties and use for automated anomaly interpretation, Geophysics, 37, 507-517.

NABIGHIAN, M.N. (1974): Additional comments on the analytic signal of two-dimensional magnetic bodies with polygonal cross-section, Geophysics, 39, 85-92.

NABIGHIAN, M.N. (1984): Toward a three-dimensional automatic interpretation of potential field data via generalized Hilbert transforms: fundamental relation, Geophysics, 49, 957-966.

NAIR, M.R., S.K. BISWAS and K. MAZUMdAR (1974): Standard curves for the interpretation of horizontalloop electromagnetic anomalies, Geol. Surv. India, Miscellaneous Publication, n. 25.

PALACKY, G.J. (1978): Selection of a suitable method for quantitative interpretation of towed bird AEM meas- urements, Geophysics, 43, 576-587.

PATRA, H. and K. MALLICK (1980): Geosounding Principles 2 (Elsevier Science Publishing Co., New York).

Roest, W.R., J. Verhoef and M. PILKington (1992): Magnetic interpretation using the $3 \mathrm{D}$ analytic signal, Geophysics, 57, 16-125.

SABET, A.H., M.S. El-GabY and A.A. Zalata (1972): Geology of the basement rocks at the northern parts of El- Shayib and Safaga sheets, Eastern Desert, Egypt, Ann. Geol. Surv., Egypt, 2, 111-128.

SCHURMANN, H.M.E. (1966): The Precambrian Along the Gulf of Suez and the Northern Part of the Red Sea, E.J. Brill, Leiden, The Netherlands, pp. 404.

WoN, I. (1980): A wide-band electromagnetic exploration method: some theoretical and experimental results, Geophysics, 45, 928-940.

WON, I.J. and D. KeISWETTER (1997): Comparison of magnetic and electromagnetic anomalies caused by underground structures, J. Envir. Eng. Geophys., 2, 115-125.

(received March 15, 2002;

accepted October 22, 2002) 